\title{
TINJAUAN LITERATUR KEUNGGULAN KOMPETITIF PADA USAHA MIKRO, KECIL DAN MENENGAH (UMKM)
}

\author{
Sopyan Saori' ${ }^{1}$, Resa Nurmala ${ }^{2}$, Kokom Komariah ${ }^{3}$ \\ 1,2,3 Administrasi Bisnis, Fakultas Ilmu Administrasi Dan Humaniora \\ Universitas Muhammadiyah Sukabumi \\ ${ }^{1}$ sopyansaori@ummi.ac.id
}

\begin{abstract}
Competitive advantage is the result of a strategy planned by a business, both in the micro, small and medium sectors. Strategic direction is manifested through the ability to generate greater profits than competitors. Many factors are equally important in generating competitiveness. Some of them are strategic factors, human resource development, knowledge management and the role of Information \& Communication Technology (ICT). From these factors will create and maintain a superior position from competitors, which is called competitive advantage. However, a thorough understanding of the state-of-art of competitive advantage is still needed. Therefore, this article aims to classify, identify scientific publications and carry out thematic analysis of current literature in order to create an extensive and detailed understanding of the field of competitive advantage. The research method is carried out by means of systematic mapping study (SMS) to examine scientific publications in the field of competitive advantage that are produced based on the focus and type of research over time. The results of this study resulted in categorization and quantification of competitive advantage studies in various dimensions as well as an overview of current research topics and trends.
\end{abstract}

Keywords: competitive advantage, competitiveness, micro, small and medium enterprises, creative industries, systemetic mapping study

\begin{abstract}
ABSTRAK
Keunggulan kompetitif adalah hasil dari strategi yang direncanakan suatu usaha, baik pada sektor mikro, kecil dan menengah. Arah strategis diwujudkan melalui kemampuan menghasilkan keuntungan lebih besar dari pada pesaing. Banyak faktor yang sama pentingnya dalam menghasilkan daya saing. Beberapa di antaranya adalah faktor strategi, pengembangan sumber daya manusia, knowledge management dan peran Information \& Communication Technology (ICT). Dari faktor tersebut akan menciptakan dan mempertahankan posisi yang unggul dari pesaing, yang disebut keunggulan kompetitif. Akan tetapi, pemahaman menyeluruh tentang state-of-art dari keunggulan kompetitif masih dibutuhkan. Oleh karena itu, artikel ini bertujuan untuk mengklasifikasikan, mengidentifikasi publikasi-publikasi ilmiah dan melakukan analisis tematik terhadap literatur terkini guna menciptakan pemahaman yang ekstensif dan terperinci dibidang keunggulan kompetitif. Metode penelitian dilakukan dengan cara systematic mapping study (SMS) untuk menelaah publikasi ilmiah dibidang keunggulan kompetitif yang dihasilkan berdasarkan fokus dan tipe riset dari waktu ke waktu. Hasil penelitian ini menghasilkan kategorisasi dan kuantifikasi studi keunggulan kompetitif dalam berbagai dimensi serta ikhtisar topik dan tren penelitian saat ini.
\end{abstract}

Kata kunci: keunggulan kompetitif, daya saing, usaha mikro kecil dan menengah, industri kreatif, systemetic mapping study 


\section{PENDAHULUAN}

Usaha Mikro, Kecil dan Menengah (UMKM) berperan dalam penyediaan lapangan kerja dan menghasilkan output yang bermanfaat bagi masyarakat Indonesia. Perkembangan UMKM pada sektor industri kreatif berkontribusi menciptakan lapangan kerja dan memberikan fleksibilitas kebutuhan dan inovasi dalam perekonomian secara keseluruhan (Hadiyati, 2011). Sektor industri kreatif diyakini mampu bertahan dikala sektor lain dilanda krisis keuangan global (Utama dan Darwanto, 2013; Maslakhah, 2017).

Tujuan penelitian ini adalah untuk menemukan temuan-temuan yang akurat dan relevan pada database electronic dipenjuru dunia. Secara keseluruhan peneliti menganalisa hasil pencarian yang relevan dengan kajian keunggulan kompetitif berdasarkan rumusan pertanyaan utama, yang meliputi:

1. RQ1: Bagaimana fokus dan lokus penelitian pada topik yang diteliti?

2. RQ2: Bagaimana tipe artikel dan metode penelitian yang digunakan?

3. RQ3: Bagaimana perkembangan topik disetiap negara dari waktu ke waktu?

\section{KAJIAN PUSTAKA}

Pemberdayaan UMKM ditengah arus globalisasi dan tingginya persaingan membuat UMKM harus mampu menghadapi tantangan global, seperti meningkatkan inovasi produk barang dan jasa, pengembangan sumber daya manusia dan teknologi, serta perluasan area pemasaran. Hal ini perlu dilakukan untuk meningkatkan daya saing UMKM itu sendiri, tujuannya agar dapat bersaing secara kompetitif pada produk-produk dalam negeri maupun asing yang kian membanjiri sentra industri dan manufaktur di Indonesia, mengingat UMKM adalah sektor ekonomi yang mampu bertahan pada era globalisasi yang penuh persaingan (Sudaryanto, 2011).

Menciptakan keunggulan kompetitif, perlu mempunyai kemampuan untuk memanfaatkan kemampuan untuk menangani masalah tertentu sebagai kemampuan tumbuh dari waktu ke waktu, untuk memanfaatkan dan menciptakan sumber daya baru, seperti keterampilan untuk memanfaatkan teknologi, atau untuk membuka peluang baru untuk pengembangan jenis baru produk. Sebuah perusahaan dikatakan memiliki keuntungan kompetitif ketika perusahaan melaksanakan strategi penciptaan nilai yang pada prosesnya akan menghasilkan tenaga-tenaga profesiomal. Akhirnya, hasil kinerja yang unggul dan keunggulan dalam produksi mencerminkan keunggulan kompetitif (Associate, S.A, 2012).

Keunggulan kompetitif adalah keuntungan lebih dari pesaing yang 
diperoleh dengan menawarkan konsumen nilai yang lebih besar, baik dengan cara harga yang lebih rendah atau dengan memberikan manfaat yang lebih besar dan layanan yang membenarkan harga yang lebih tinggi, Porter (2001). Menurut Barney dan Clark (1991) dalam ResourceBased Theory: Creating and Sustaining Competitive Advantage, menyebutkan bahwa sumber keunggulan kompetitif meliputi sumber daya, orisinil, tidak dapat ditiru, dan tidak ada substitusinya. Sumber daya yang dimaksud meliputi semua aset, kapabilitas, proses organisasional, karakteristik perusahaan, informasi, pengetahuan dan sebagainya yang mana sumber daya ini berada dalam kendali perusahaan untuk implementasi strategi agar tercapai keefektifan dan efisiensi (Barney, 1986; 1988; 1991; 1996; 2001).

Keunggulan kompetitif yang telah diraih seharusnya dapat terus dipertahankan karena dengan adanya keunggulan makin banyak kompetitor yang memperhatikan titik lengah suatu usaha tersebut, oleh karena itu UMKM harus terus konsisten dalam menjaga keunggulanya (Russell \& Millar 2014). Keunggulan kompetitif dapat juga dilihat dengan melalui evaluasi pelanggan yang dapat diciptakan perusahaan melalui fasilitas-fasilitas pelayanan yang dapat menampung segala macam keluhan atau saran yang ditujukan konsumen untuk perusahaan demi perbaikan menuju yang lebih berkualitas. Untuk mewujudkan strategi tersebut, UMKM harus proaktif dan inovatif dalam merancang strategi usaha seperti pemenfaatan teknologi informasi dan komunikasi (ICT). Pengaturan strategi yang baik menjadi kunci kesuksesan bagi UMKM untuk dapat menjadi unggul dengan adanya antisipasi dalam persaingan pasar (Tarabieh et al. 2015).

Oleh karena itu, untuk mendapatkan perspektif penelitian yang ada, peneliti melakukan studi pemetaan sistematis (systematic mapping study). Studi ini merupakan tinjauan literatur dengan menggunakan systematic mapping study (SMS) mengenai keunggulan kompetitif, meskipun ada beberapa tinjauan literatur terkait keunggulan kompetitif yang dilakukan di Indonesia (Handayani et al., 2013; Napitupulu et al., 2013; Susanti et al., 2015; Ginting, 2015; Roostika et al., 2015; Widodo, 2015; Tjahjaningsih et al., 2016; Rufaidah, 2016; Ismail, 2016; Sulistyo et al., 2016; Samsir et al., 2017; Budiarto et al., 2017; Mustofa et al., 2017; Lukiastuti et al., 2017; Ardyan et al., 2017), namun hanya sedikit yang membahas spesifik systematic mapping study (SMS) mengenai keunggulan kompetitif (Kahkonen \& Smolander, 2013). Maka, tujuan dari penelitian ini adalah menyediakan peta literatur yang ada 
untuk mencapai hasil yang bermanfaat bagi penggunaan praktis dan juga untuk bagi akademisi untuk mengidentifikasi kesenjangan penelitian (gaps) di masa yang akan datang (Akkermans, Bogerd, \& van Wassenhove, 2003).

Tujuan dari studi pemetaan sistematis ini adalah untuk membentuk latar belakang riset lebih lanjut serta mendapatkan wawasan yang lebih dalam tentang kajian keunggulan kompetitif. Didalam penelusuran peneliti menggunakan database electronic International untuk menemukan artikel yang membahas tentang keunggulan kompetitif dibidang UMKM. Studi SMS merupakan metode yang tepat sebagai pendekatan studi literatur karena didukung dengan 29,628 artikel terkait keunggulan kompetitif dari penelusuran di Scopus electronic database (Kitchenham, 2007; Petersen et al., 2008).

\section{METODE PENELITIAN}

Penelitian ini menggunakan systematic mapping study (SMS) yang mana merupakan studi sekunder. SMS berakar pada study literature review (SLR) yang dikenalkan pada riset-riset teknologi informasi (Kitchenham. B, 2004). Penelitian degan pendekatan SLR bertujuan untuk mengidentifikasi, mengevaluasi, dan menafsirkan semua sumber literatur yang tersedia dan relevan, terkait dengan pertanyaan penelitian yang telah dirumuskan (Kitchenham. B, 2004, 2007; Petersen et al., 2008; Barbosa dan Alves, 2011; Banaeianjahromi \& Smolander, 2016, Rizal, 2017). Alasan paling umum untuk melakukan SLR adalah: pertama, meringkas bukti yang ada tentang topik tersebut; Kedua, untuk mengidentifikasi kesenjangan dalam penelitian saat ini dan memberikan saran untuk penyelidikan di masa yang akan datang; Dan ketiga, untuk memberi latar belakang memposisikan kegiatan penelitian baru (Kitchenham. B, 2004).

SMS diterapkan untuk menguraikan jenis aktivitas penelitian yang telah dilakukan dalam penelitian ini. SMS menjelaskan penelitian pada tingkat tinggi dan memetakan penelitian dari pada menyelidiki pertanyaan penelitian secara rinci (Petersen et al., 2008). Dengan kata lain, SMS dapat dianggap sebagai metode untuk mendapatkan gambaran umum tentang area penelitian tertentu (Kitchenham et al., 2011), karena, penelitian SMS menggali informasi secara terperinci (Brereton et al, 2007).

\section{Langkah pencarian}

Untuk menambah keakuratan studi SMS, proses pencarian dan analisis harus seakurat mungkin. Dengan demikian, pada bagian ini mencirikan proses pemilihan sumber data, strategi penerapan untuk 
membuat string pencarian, dan menentukan kriteria esklusi dan inklusi.

Penelitian ini mengadopsi proses pencarian dari penelitian Petersen et al. (2008) dan Banaeianjahromi dan Smolander (2016). Dalam proses ini, setiap langkah memiliki hasil dan peta sistematis (systematic mapping) adalah hasil akhir dari proses pemetaan. Pada gambar $1 \mathrm{kami}$ mengilustrasikan proses SMS lengkap yang digunakan dalam penelitian ini, kami mengacu pada penelitian yang dilakukan dan sesuai instruksi oleh Kitchenham (2004) dan Petersen et al (2008).

Peneliti melakukan pencarian secara online pada database elektronik terindeks scopus. Scopus merupakan pangkalan data pustaka yang mengandung abstrak dan artikel jurnal akademik internasional bereputasi yang termasuk dalam kriteria Direktorat Jendral Pendidikan Tinggi (DIKTI) Republik Indonesia.

\section{Gambar 1. Proses SMS (Pencarian)}

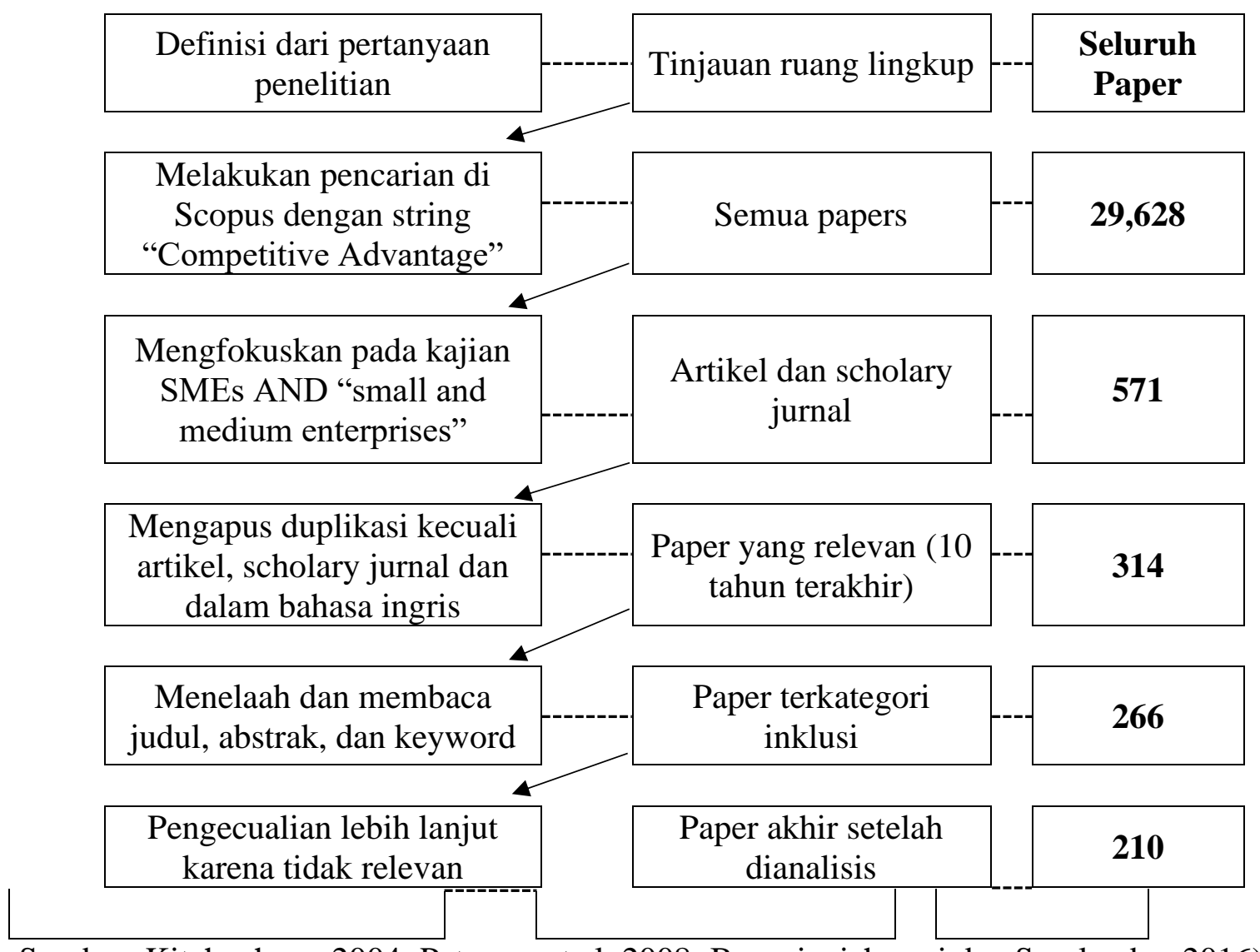

Sumber: Kitchenham, 2004; Petersen et al, 2008; Banaeianjahromi dan Smolander, 2016) 
String pencarian atau kata kunci pencarian dibuat dengan menggunakan strategi dari Banaeianjahromi dan Smolander (2016) dengan mengacu dari penelitian Barbosa and Alves (2011). Langkah pertama adalah mendefenisikan kata kunci utama. langkah kedua adalah memeriksa penelitian-penelitian yang medium enterprises"), peneliti menemukan 571 hasil.

Namun apabila string pencarian hanya tidak menggunakan Boolean hasil yang ditemukan dengan string "competitive advantage" ditemukan sebanyak 29.628 hasil. String pencarian diatas diterapkan untuk pencarian pada

Tabel 1. Keriteria Inkusi dan Eksklusi

\begin{tabular}{ll}
\hline Inklusi & Eksklusi \\
\hline 1. Penelitian yang berfokus & 1. Makalah yang tidak membahas tentang \\
pada penelitian keunggulan & keunggulan kompetitif \\
kompetitif & 2. Bahasa lain selain bahasa Inggris \\
2. Bahasa Inggris & 3. Disertasi, tesis, bagian buku, deskripsi \\
3. Hanya artikel dan scholary & produk, presentasi, laporan kerja, literatur \\
journals & perdagangan, catatan editorial, literatur yang \\
4. Makalah yang sudah & tidak jelas \\
melewati peer reviewed & 4. Makalah yang belum melewati peer \\
& reviewed \\
& 5. Penelitian duplikat \\
\hline
\end{tabular}

sudah dikenal dibidang keunggulan kompetitif. Ketiga yaitu mencari bentuk kata kunci alternatif untuk digunakan pada proses pencarian,

Menurut Banaeianjahromi dan Smolander (2016) langkah terakhirnya menggunakan operator Boolean yang fungsinya untuk mensintesis menajadi satu string pencarian, namun pada penelitian ini tidak menggunakan operator Boolean AND atatpun $O R$ karena pada tahap ketiga peneliti menemukan bahwa apabila kombinasi stringnya adalah "competitive advantage" AND (sme OR smes OR "small and medium enterprise" OR "small and semua bagian artikel, seperti judul, abstrak, kata kunci pada database elektronik scopus. Proses pencarian dimulai pada tanggal 30 November 2017 (Barbosa \& Alves, 2011).

Selanjutnya, langkah untuk menentukan kategori artikel pengecualian yang disebut kriteria eksklusi dan artikel inklusi yang merupakan salah satu kegiatan studi pemetaan untuk tidak mengikutsertakan artikel yang tidak relevan dan mencakup artikel yang relevan (Petersen et al., 2008). Pada penelitian ini, kami merumuskan kriteria eksklusi dan 
inklusi untuk mempermudah pemetaan

(Tabel

\section{Langkah pengklasifikasian}

Pada proses pemetaan sistematis, untuk menganalisis dan mengknlasifikasikan artikel yang sudah diseleksi berdasarkan kriteria, peneliti merumuskan tiga aspek untuk pengklasifikasian artikel yang ditemukan yang telah relevan. Pada kategori pertama kami mengelompokkan artikel berdasarkan fokus penelitian (research focus) dengan acuan Petersen et al. (2008). Kategori kedua mendefinisikan tipe artikel (paper type) berdasarkan klasifikasi yang disajikan dalam Wieringa et al. (2005). Selanjutnya pada kategori ketiga berdasarkan metode penelitian dengan rujukan dari penelitian Musianto (2002). Tabel 2 menjelaskan ketiga kategori pada proses klasifikasi pada penelitian ini.

Tabel 2. Kategori Klasifikasi

\begin{tabular}{ll}
\hline Paper Type & Penjelasan \\
\hline Validation Research & $\begin{array}{l}\text { Metode investigasi baru dan belum diterapkan dalam praktik. } \\
\text { (percobaan / observasi) }\end{array}$ \\
\hline Evaluasi Research & $\begin{array}{l}\text { Metode investigasi diimplementasikan dalam praktek dan } \\
\text { disajikan dalam metode evaluasi }\end{array}$ \\
\hline Solution Proposal & $\begin{array}{l}\text { Solusi untuk masalah diajukan, usulan solusi ini bisa berupa } \\
\text { pendekatan baru atau berlaku dan pendekatan yang ada. }\end{array}$ \\
\hline Philosophical Paper & $\begin{array}{l}\text { Penelitian ini memperkenalkan perspektif baru tentang } \\
\text { sesuatu yang ada dengan menggunakan taksonomi atau } \\
\text { kerangka konseptual. }\end{array}$ \\
\hline Methods & Penjelasan \\
\hline Metode Kulitatif & $\begin{array}{l}\text { Metode Kualitatif disajikan Rapid Assessment Process, data } \\
\text { sekunder, etnografis, Focus Group Discussions, In-Depth } \\
\text { Interviews, buku harian dan analisa bahasa. }\end{array}$ \\
\hline Metode Kuantitatif & $\begin{array}{l}\text { Metode Kuantitatif disajikan rancangan sampel, hipotesis dan } \\
\text { pengujiannya, yang kesemuanya berupa perumusan statistik. }\end{array}$ \\
\hline Mix Methods & $\begin{array}{l}\text { Mix-method penelitian adalah metode yang memadukan } \\
\text { pendekatan kualitatif dan kuantitatif dalam hal metodologi } \\
\text { (seperti dalam tahap pengumpulan data), dan kajian model }\end{array}$ \\
campuran memadukan dua pendekatan dalam semua tahapan \\
proses penelitian (Abbas, 2010)
\end{tabular}




\begin{tabular}{|c|c|}
\hline $\begin{array}{l}\text { Information and } \\
\text { Communication } \\
\text { Technology (ICT) }\end{array}$ & $\begin{array}{l}\text { Payung besar terminologi yang mencakup seluruh peralatan } \\
\text { teknis untuk memproses dan menyampaikan informasi. TIK } \\
\text { mencakup dua aspek yaitu teknologi informasi dan teknologi } \\
\text { komunikasi. }\end{array}$ \\
\hline Organizational capability & $\begin{array}{l}\text { Kemampuan organisasi perusahaan untuk membantu } \\
\text { organisasi mengembangkan kemampuan seperti skill, } \\
\text { pengalaman, kualitas karyawan guna mencapai tujuan } \\
\text { perusahaan. }\end{array}$ \\
\hline Innovation Capability & $\begin{array}{l}\text { Kemampuan untuk menciptakan inovasi, gagasan baru, } \\
\text { konsep baru dan ide-ide }\end{array}$ \\
\hline $\begin{array}{l}\text { Dynamic } \\
\text { Capability }\end{array}$ & $\begin{array}{l}\text { Mencakup manajemen, riset dan pengembangan, produk, } \\
\text { manufaktur, human resources dan organisasi. }\end{array}$ \\
\hline Business development & $\begin{array}{l}\text { Pengembangan perusahaan baik melalui strategi corporate } \\
\text { parenting (anak perusahaan), pengembangan oraganisasi, } \\
\text { pengembahan strategi marketing dan lainnya. }\end{array}$ \\
\hline Knowledge Managemen & $\begin{array}{l}\text { Serangkaian strategi, sistem dan teknik yang digunakan oleh } \\
\text { individu, team dan korporasi untuk mengelola 'knowledge' } \\
\text { atau pengetahuan. }\end{array}$ \\
\hline $\begin{array}{l}\text { Entrepreneurial } \\
\text { Orientation }\end{array}$ & $\begin{array}{l}\text { Mancakup emapat dimensi yaitu; autonomy, proactive, } \\
\text { taking-risk, dan innovation. }\end{array}$ \\
\hline $\begin{array}{l}\text { Entrepreneurial } \\
\text { Marketing }\end{array}$ & $\begin{array}{l}\text { Kegiatan pemasaran yang dilakukan oleh usaha baru dan } \\
\text { usaha mikro dan kecil. }\end{array}$ \\
\hline Investment & $\begin{array}{l}\text { Dukungan permodalan dari pihak Lembaga keuangan Bank } \\
\text { dan Non-Bank. }\end{array}$ \\
\hline
\end{tabular}

Sumber: Olahan Peneliti (2017), berdasarkan Penelitian Musianto, (2002); Wieringa et al (2005); Petersen et al (2008).

\section{HASIL DAN PEMBAHASAN}

\section{Hasil Penelitian}

Bagian ini merupakan hasil pemetaan berdasarkan dari pertanyaan penelitian. Berdasarkan hasil pemetaan dari 210 artikel mengenai competitive advantage dikelompokan dengan menggunakan aplikasi Microsoft Excel 2016 dengan kategori research focus, research locus, mothods, paper type, dan perkembangan penelitian dipenjuru dunia yang dipublis oleh scopus. Setelah melakukan pemetaan secara sistematis ditemui 15 jenis dokumen artikel yang berasal dari Indonesia.

\section{Fokus dan Lokus Penelitian (RQ1)}

Untuk menjawab RQ1, kami mengklasifikasikan 210 artikel pada area topik penelitian (research focus) dengan kategori: environmental factor, information and communication technology (ict), organizational capability, innovation capability, dynamic capability, business development, knowledge managemen, entrepreneurial orientation, entrepreneurial marketing, investment. 


\section{Gambar 2. Fokus Penelitian}

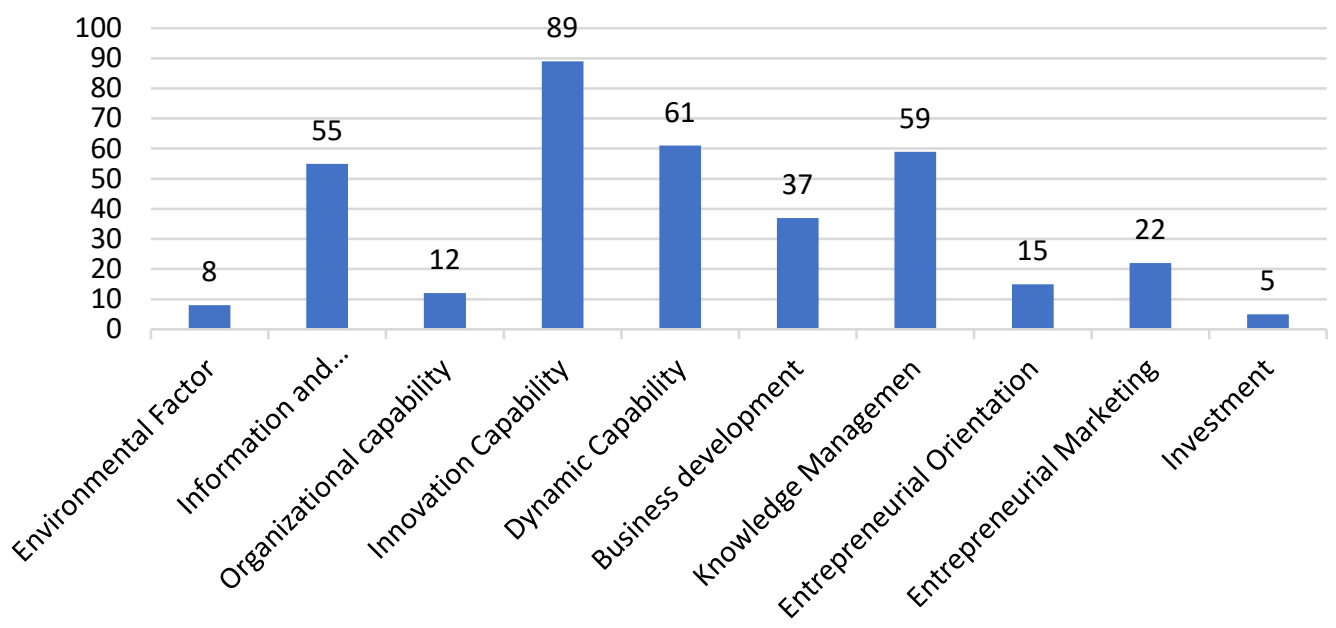

Sumber: Data Olahan Peneliti, 2017

Gambar 2 merupakan persentase dari topik yang diteliti, topik yang banyak diteliti adalah penelitian dengan fokus penelitian innovation capability sebanyak 89 (25\%), Dynamic Capability sebanyak 61 (17\%), Knowledge management sebanyak 59 (16\%), Information and Communication Technology (ICT) sebanyak 55 (15\%) dan yang paling sedikit adalah penelitin dengan topik environmental factor dan investment yang berjumlah masing-masing $8(2 \%)$ dan 5 (1\%) dari total $210(100 \%)$ penelitian.

Pada kajian competitive advantage, peneliti dominan meneliti pada UMKM yang berada disuatu wilayah, baik kota maupun desa dengan total temuan 92 penelitian. Selanjutnya lokus penelitian yang banyak dilakukan adalah pada industri dengan temuan 42 penelitian. Kemudian, pada sektor industri kreatif terdapat 15 penelitian, temuaan yang sama dijumpai pada lokus penelitian High-tech SMEs (perusahaan teknologi). Akan tetapi, peneliti menemukan bahwa terdapat penelitian atau riset pada competitive advantage yang tidak memiliki lokus penelitian dalam artian tempat yang diteliti, hal ini peneliti simpulkan bahwa ada beberapa penelitian yang menggunakan tipe artikel filosofis. (Gambar 3). 


\section{Gambar 3. Lokus Penelitian}

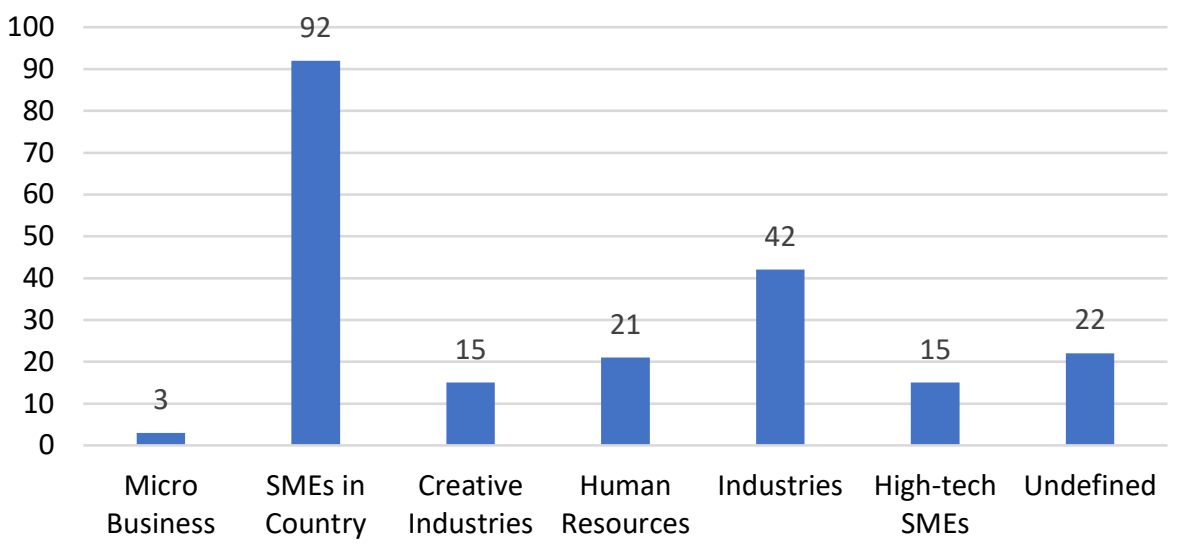

Sumber: Data Olahan Peneliti, 2017

Tipe Artikel dan Metode Penelitian (RQ2)

Tipe artikel penelitian menunjukkan klasifikasi penelitian yang mengacu pada penelitian Wieringa et al. (2005), dimana penelitian dikelompokkan menjadi empat kategori: penelitian validasi (validation research); penelitian evaluasi (evaluation research); solution proposal; philosophical papers Untuk memberikan jawaban dari RQ2, kami mengkategorikan 210 penelitian hasil pemetaan klasifikasi tersebut.

\section{Gambar 4. Tipe Artikel}

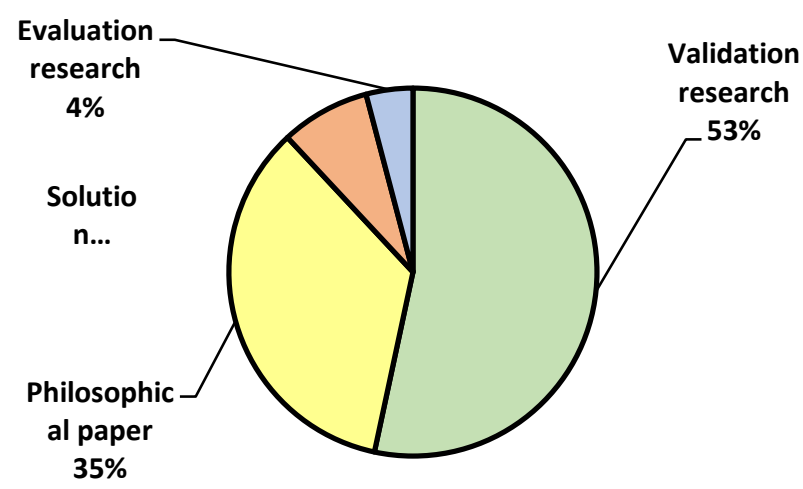

Sumber: Data Olahan Peneliti, 2017

kategori pengklasifikasian menurut

Gambar 4 menggambarkan distribusi tipe artikel (paper type) berdasarkan
Wieringa et al. (2005). Berdasarkan hasil pemetaan secara sistematis (systematic 
mapping study), tipe artikel yang paling sering digunakan adalah penelitian validasi (validation research) dengan total sebanyak $143(53 \%)$ penelitian. tipe artikel yang paling sering selanjutnya adalah penelitian filosofis (philosophical papers) dengan jumlah sebanyak $93 \quad(35 \%)$ penelitian. Selanjutnya adalah tipe artikel solusi yang berjumlah $21(8 \%)$ dan yang paling sedikit adalah tipe artikel evaluasi sebanyak $11(4 \%)$ penelitian.

\section{Pendekatan penelitian dengan} menggunakan metode kuantitatif adalah metode yang paling banyak dilakukan, karena sifatnya adalah menguji dan mengevaluasi. Total artikel yang melakukan penelitian menggunakan pendekatan kuantitatif ada sebanyak 119 (57\%) penelitian. Selanjutnya diikuti dengan atikel yang menggunakan metode kualitatif sebanyak 80 (38\%) penelitian. Dan mixed-methods sebanyak 11 (5\%) penelitian.
Klasifikasi metode penelitian merujuk penelitian Musianto (2002). Pendekatan metode penelitian yang digunakan pada pemetaan sistematis ini adalah pendekatan kuantitatif, kualitatif dan mixed-method. Akumulai total temuan dari 210 jurnal bereputasi scopus digambarkan pada gambar 5 .

\section{Tren publikasi pada setiap Negara dari waktu ke waktu (RQ3)}

Berdasarkan hasil pemetaan ditemui bahwa negara terbanyak menghasilkan penelitian tentang competitive advantage adalah United Kingdom dengan total 35 publikasi, diikuti Malaysia sebanyak 26 publikasi. Yang menarik adalah pada urutan ketiga terbanyak adalah Indonesia dengan banyak 17 publikasi. Gambaran tren penelitian tentang competitive advantage digambarkan pada Gambar 6.

\section{Gambar 6. Perkembangan publikasi disetiap negara}

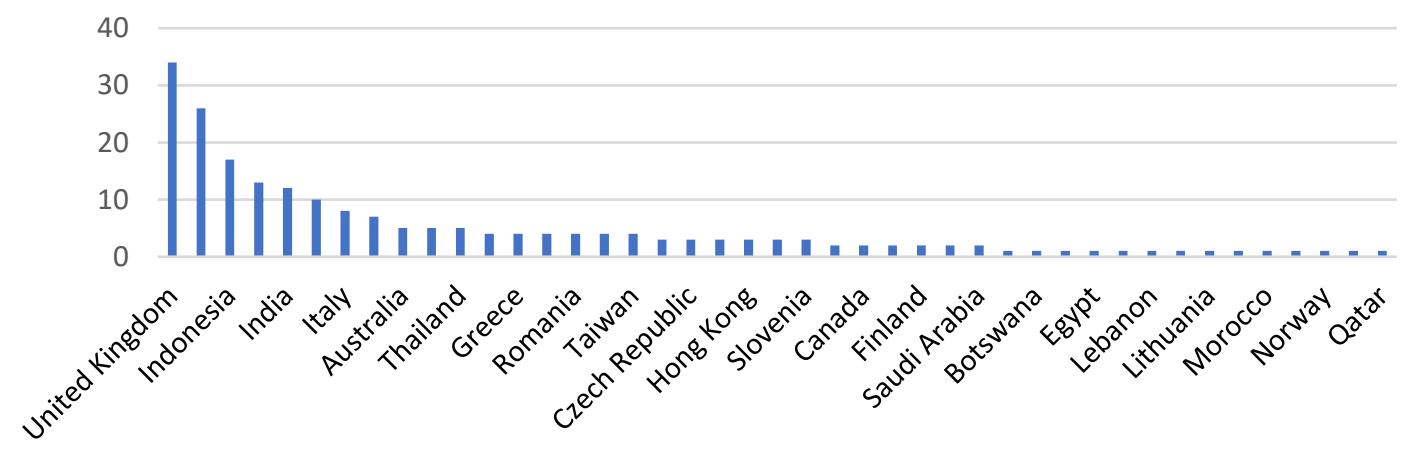


Kemudian Gambar 7 merupakan tren penelitian yang dipublikasi pada media database elektronik 10 (sepuluh) tahun terakhir yang dimulai pada tahun 2007, namun dari hasil penelusuran kami menemukan bahwa penelitian competitive advantage mulai banyak setelah Porter pada tahun 1980 mempublikasikan hasil risetnya yang berjudul competitive strategy.

\section{Gambar 7 Perkembangan publikasi dari tahun ke tahun}

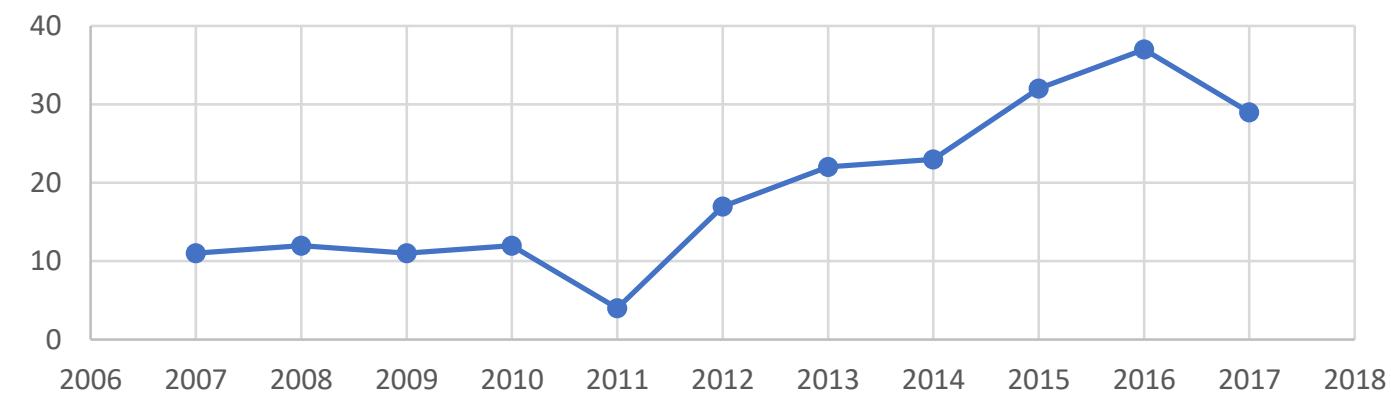

Sumber: Data Olahan Peneliti, 2017

\section{KESIMPULAN}

Dalam rangka meningkatkan daya saing baik disektor usaha mikro, kecil dan menengah (UMKM), perlu adanya penerapan konsep keunggulan kompetitif (competitive advantage). Ada jutaan pesaing yang akan menjadi ancaman nyata yang mampu mematikan usaha. Dampaknya adalah pertumbuhan perekonomian yang berakar pada kebertahanan usaha. Peran akademisi, praktisi, Lembaga riset serta pemerintah untuk menghasilkan kajian-kajian terkait keunggulan kompetitif suatu usaha. Keterkaitan antara pihak akademisi, praktisi, lembaga riset serta pemerintah dengan pelaku usaha, perusahaan, industri, serta pelaku usaha adalah pengembangan konsep, gagasan dan ide tentang competitive advantage.

Penelitian ini memetakan literature competitive advantage yang ada pada database ilmiah scopus. Motivasi utama dari studi yang dipertakan adalah untuk 
memberikan gambaran umum literatur yang ada tentang competitive advantage sebagai solusi untuk memenangkan persaingan usaha.

Peneliti menerapkan metode systematic mapping study (Kitchenham, 2004; Petersen et al, 2008; Banaeianjahromi dan Smolander, 2016), untuk menentukan fokus apa yang telah dikaji dalam area penelitian ini. Dari 210 artikel penelitian yang telah di petakan secara sistematik, kami menyimpulkan bahwa:

1) Topik yang banyak diteliti adalah penelitian dengan fokus penelitian Innovation Capability (25\%), Dynamic Capability (17\%), Knowledge management (16\%) dan Information and Communication Technology (15\%) pada usaha mikro kecil dan menengah sebanyak 44\% (92 penelitian dari 210)

2) Tipe artikel yang paling sering digunakan adalah penelitian validasi (validation research) dengan total sebanyak $143 \quad$ (53\%) artikel, menggunakan pendekatan penelitian kuantitatif (57\%).

3) Negara terbanyak yang menghasilkan penelitian tentang competitive advantage adalah United Kingdom dengan total 35 publikasi, Malaysia sebanyak 26 publikasi, dan Indonesia dengan banyak 17 publikasi.

Metode penelitian yang diadopsi SMS adalah metode penelitian praktis untuk mengenali topik yang tepat untuk diteliti, serta area mana yang diperlukan untuk lebih banyak penelitian. Hasil penelitian ini memberikan panduan untuk membantu peneliti dalam merencanakan penelitian dimasa yang akan datang melalui penemuan kesenjangan penelitian (Gaps).

\section{DAFTAR PUSTAKA}

Akkermans, H. A., Bogerd, P. Y., \& van Wassenhove, L. N. (2003). The impact of ERP on supply chain management: Exploratory findings from a European Delphi study. European Journal of Operation Research, 284-301.

Anggadwita, G., Luturlean, B., Ramadani, V., \& Ratten, V. (2017). Sociocultural environments and emerging economy entrepreneurship: Women entrepreneurs in Indonesia. Journal of Entrepreneurship in Emerging Economies 9 (1), 85-96.

Ardyan E., Nurtantiono A., Istiyanto B., Rahmawan G. (2017). Green innovation capability as driver of sustainable competitive advantages and smes marketing performance. International Journal of Civil Engineering and Technology

Badan Pusat Statistik Kota Bandung. (2016, May 22). Statistik Daerah 
Kota bandung Tahun 2016.

Retrieved from Badan Pusat

Statistik Kota Bandung:

https://bandungkota.bps.go.id

Banaeianjahromi., $\mathrm{N} \&$ Smolander., $\mathrm{K}$. (2016)."What do we know about the role of enterprise architecture in enterprise integration? A systematic mapping study", Journal of Enterprise Information Management, Vol. 29 Iss 1 pp. 140 $-164$

Barbosa, O., \& Alves, C. (2011). A Systematic Mapping Study on software ecosystem. Workshop and software ecosystem, Brussels, pp. 15-26.

Barbosa, O., \& Alves, C. (2011). A Systematic Mapping Study on software ecosystem. Workshop and software ecosystem, Brussels, pp. 15-26.

Barney., J. B. \& Clark., Delwyn N. (2001). Resource-Based Theory: Creating and Sustaining Competitive Advantage. Oxford University Press Inc., New York.

Barney., J. B. (1986). Organizational culture: can it be a source of sustained competitive advantage?. Academy o/Monogemen/Review. 1986, Vol. 11. No. 3. 656-665.

Barney., J. B. (1988). Returns To Bidding Firms In Mergers And
Acquisitions: Reconsidering The Relatedness Hypothesis. Strategic Management Journal, Vol. 9, 71-78 (1988).

Barney., J. B. (1991). Firm Resources and Sustained Competitive Advantage. Journal of Management 1991 17: 99

Barney., J. B. (1996). Information Technology and Sustained Competitive Advantage: A Resource-Based Analysis.

Executive Overview. Page 487

Barney., J. B. (2001). The resource-based view of the firm: Ten years after 1991. Journal of Management 27 (2001) 625-641

Bernardin, John H., dan Russel, Joyce E. A. (2013). Human Resources Managment: An. Experiental Approach. Jakarta: Gramedia Pustaka

Brereton, P., Kitchenham, B. A., Budgen, D., Turner, M., \& Khalil, M. (2007). Lessons from applying the systematic literature review process within the software engineering domain. Journal of Systems and Software, Volume 80, Issue 4, Pages 571-583.

Budiarto D.S., Prabowo M.A., Herawan T. (2017). An integrated information system to support supply chain management \& Performance in 
SMEs. Journal of Industrial Engineering and Management.

Dinas Koperasi UKM dan Perindustrian Perdagangan Kota Bandung. (2016). Laporan Kinerja Intansi Pemerintah ( LKIP ). Bandung: Pemerintah Kota.

Ginting G. (2015). Network resources as a key determinant of small medium enterprises/SMES export performance (Case: Creative industry in Indonesia). International Journal of Applied Business and Economic Research

Hadiyati, E. (2011). Kreativitas dan Inovasi Berpengaruh Terhadap Kewirausahaan Usaha Kecil. Jurnal Manajemen Dan Kewirausahaan, Vol.13, NO. 1, 816.

Handayani P.W., Hidayanto A.N., Budi I.(2013). Business process requirements for indonesian small medium enterprises (SMEs) in implementing enterprise resource planning (ERP) and ERP systems comparison. Journal of Computers (Finland)

Herawati, T., Rudatin, C. L., \& Akbar, D. (2014). Potensi Kota Bandung Sebagai Destinasi Incentive Melalui Pengembangan Ekonomi Kreatif. Epigram Journal, Vol. 11 No.2 Oktober, 95-102.
Ismail T. (2016). Culture control, capability and performance: Evidence from creative industries in Indonesia. Asian Review of Accounting

Kahkonen, T., \& Smolander, K. (2013). ERP Integration: A Systematic Mapping Study. Proceedings of the 15th International Conference on Enterprise Information Systems ISBN 978-989-8565-59-4, Angers, France, 23-35.

Kahkonen, T., \& Smolander, K. (2013). ERP Integration: A Systematic Mapping Study. Proceedings of the 15th International Conference on Enterprise Information Systems ISBN 978-989-8565-59-4, Angers, France, 23-35.

Kitchenham, B. (2004). Procedures for performing systematic reviews. Keele University, Keele.

Kitchenham, B. (2007). Guidelines for performing Systematic Literature Reviews in Software Engineering. EBSE Technical Report, School of Computer Science and Mathematics, Keele University, UK, 1-57.

Lukiastuti F., Sutanto H.A., Imaningati S. (2017). Self-reliance improvement model for women batik SMEs: (Study at kliwonan village small 
batik industrial center). Advanced Science Letters.

Maslakhahh, M. (2017, Maret 18). Peran Pemerintah Dalam Meningkatkan Daya Saing Umkm (Studi Pada Pengrajin Logam Pisau Di Desa Hadipolo Kecamatan Jekulo Kabupaten Kudus). Diambil kembali dari Perpustakaan STAIN Kudus:

http://eprints.stainkudus.ac.id/841/

Musianto, L. (2002). Perbedaan pendekatan kuantitatif dan pendekatan kualitatif dalam metode penelitian. Jurnal Manajemen \& Kewirausahaan. Vol. 4. 2.

Mustofa M.S., Ngabiyanto, Santoso A.B. 2017. Innovation and social capital in the development of embroidery industry in Nalum sari sub district of Jepara regency, central Java (a study in Nalum sari and Daren Villages). International Journal of Applied Business and Economic Research

Napitupulu T.A., Ika L.R. (2013). B2B website's model of satisfaction and benefit: A case of SME in Indonesia. International Business Management

Petersen, K. F. (2008). Systematic mapping studies in software engineering. 12th International Conference on
Evaluation and Assessment in software engineering, p.1.

Porter, M. E. (1980). Competitive strategy: techniques for analyzing industries and competitors: with a new introduction1 Michael E. Porter. New York, United States of America: The Free Press; First Free Press Edition 1980; ISBN 0-68484148-7.

Roostika R., Wahyuningsih T., Haryono S. (2015). The impacts of external competitiveness factors in the handicrafts industry. Polish Journal of Management Studies

Rufaidah P. (2016). Dynamic capability in branding strategy development. International Journal of Economics and Management

Samsir, Nursanti A., Zulfadil. (2017). The effect of product innovation as mediation in relationship between knowledge management to competitive advantage (Case study in SME of typical food products of Riau Indonesia). International Journal of Economic Research.

Sudaryanto, Ragimun. 2011. Strategi Pemberdayaan UMKM Menghadap i Pasar. Bebas Asean. Yogyakarta: Kedaulatan Rakyat.

Sulistyo H., Siyamtinah. (2016). Innovation capability of SMEs through entrepreneurship, 
marketing capability, relational capital and empowerment. Asia Pacific Management Review

Susanti A.A., Arief M. (2015). The effect of dynamic capability for the formation of competitive advantage to achieve firm's performance (Empirical study on Indonesian credit co-operatives). Advanced Science Letters

Tjahjaningsih E., Rozak H.A., Handayani D., Utomo A.P. (2016). Development and empowerment of Semarang batik craftsmen based on assistance strategy of fractal batik in the effort to build sustainable competitive advantage. International Journal of Applied Business and Economic Research

Utama, D. D., \& Darwanto, D. (2013). Pengembangan Usaha Mikro Kecil Dan Menengah (Umkm) Berbasis Ekonomi Kreatif Di Kota Semarang. Undergraduate thesis, Fakultas Ekonomika dan Bisnis

Widodo, Shahab M.A. (2015). The model of human capital and knowledge sharing towards sustainable competitive advantages. Problems and Perspectives in Management

Wieringa, R., Maiden, N., \& Mead, N. (2005). Requirements engineering paper classification and evaluation criteria: a proposal and a discussion.

Springer-Verlag London Limited 2005. 